\title{
Direct Torque Control of Dual Three-Phase Permanent Magnet Synchronous Motor
}

\author{
Fouad Labchir ${ }^{*}$, Mhammed Hasoun ${ }^{2}$, Aziz El Afia ${ }^{3}$, Karim Benkirane ${ }^{4}$ and Mohamed Khafallah $^{5}$ \\ ${ }^{1,5}$ Hassan II University, Departement of Electrical Engineering, National High School of Electricity and Mechanics "ENSEM", Casa, \\ Morocco. \\ ${ }^{3}$ Hassan II University, Departement of Electrical Engineering, National High School of Arts and Crafts "ENSAM", Casa, Morocco. \\ ${ }^{2,4}$ Royal Navy, Departement of Electrical Engineering, Navy Royal School "ERN", Casa, Morocco
}

\begin{abstract}
In this paper a direct torque control strategy for dual three-phase permanent magnet synchronous motor (DTP-PMSM) is presented, the machine has two sets of three-phase stator windings spatially phase shifted by 30 electric degrees. In order to reduce the stator harmonic current, torque and flux are controlled based on regulators and Vector Space Decomposition technique. The proposed approach has the benefits of low stator current distortion and low torque ripple. The validity and the efficiency of the selected technique are confirmed by simulation results.
\end{abstract}

\section{Introduction}

In the domain industry, conventional three-phase electric machines are mainly used. Recently, the use of electric machines with more than three phases has significantly increased, particularly for high power applications such as system propulsion. These machines usually known as multiphase machines which are existing in the domain various that is automobile, avionics, and maritime [2-8]; and provide several significant advantages such as lower torque pulsations and higher reliability [1].

Dual-Three Phase (DTP) Machines are characterized by the multiphase structure having two sets of three-phase stator windings within the same stator frame, and are spatially shifted by 30 electrical degrees [1].

Among all DTP machines used, the Dual Three Phase Permanent Magnet Synchronous Motor (DTP-PMSM) is the most used one. It has a high fault tolerance and reliability [9].

A high-performance control of DTP-PMSM is based on the Vector Space Decomposition (VSD) [10]. The VSD theory for DTP induction motor was presented in [10]. In relation to the VSD strategy, the overall machine model is transformed into three decoupled subspaces, written in three independent space coordinates, identified as, $(\alpha, \beta)$ torque-component, $(\mathrm{z} 1, \mathrm{z} 2)$ harmonic-component and (o1, o2) zero-sequence, respectively [11-17].

Direct Torque Control (DTC) for DTP has been studies in recent years. The key problem of such a system is the occurrence of harmonic current in stator windings [18]. This control and VSD theory are introduced into DTC of dual three-phase induction motor $[19,20]$. Torque and flux control based on regulators [21, 22] and VSD technique
$[23,24]$ of DTP- PMSM is proposed in this paper. It can reduce the torque ripple and harmonic current.

When applying the DTC for the DTP-PMSM, important harmonic stator currents are usually observed. These currents cause losses in the stator and thus effect the machine's efficiency. According to the VSD technique, the basic DTC does not permit the control of the harmonics that seem in the subspace (z1, z2).

The rest of this paper is structured as follows: in section 2, the machine model will be described based on VSD. Section 3 relates the conventional (DTC) approach. Section 4 includes simulation results to approve the validity of the proposed technique. Finally, conclusion is drawn in section 5 .

\section{Modelling of machine's system}

The DTP-PMSM model and VSI-fed drive are illustrate in two Figures 1and 2.

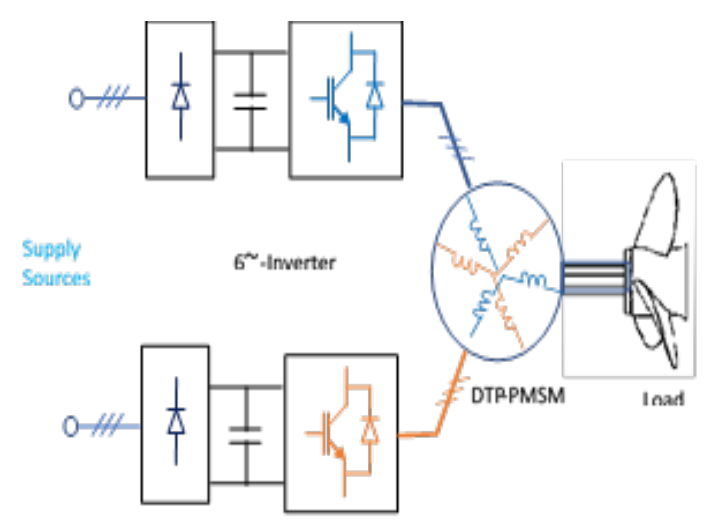

Fig. 1. The DTP-PMSM model and its power supply

\footnotetext{
* Fouad Labchir: labchirfouad69@gmail.com
} 


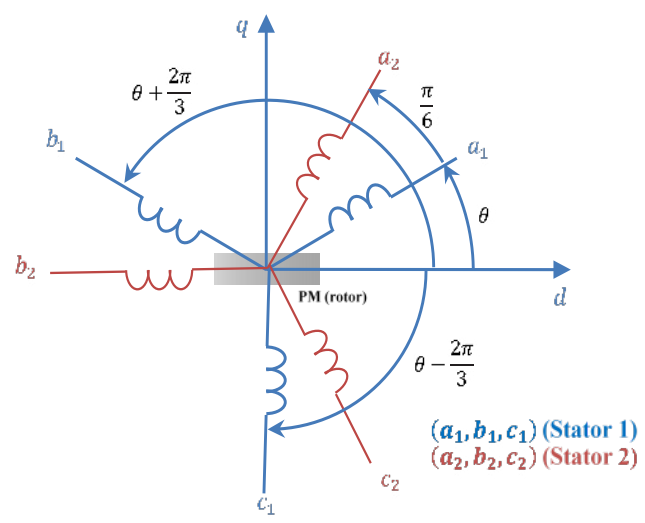

Fig. 2. The DTP-PMSM windings

The VSD theory [10] allows us to get an applied model appropriate for control. The latter is based on the decoupling transformation matrix which is expressed by (1):

$T=\frac{1}{\sqrt{3}}\left[\begin{array}{cccccc}1 & -\frac{1}{2} & -\frac{1}{2} & -\frac{\sqrt{3}}{2} & \frac{\sqrt{3}}{2} & 0 \\ 0 & \frac{\sqrt{3}}{2} & -\frac{\sqrt{3}}{2} & \frac{1}{2} & \frac{1}{2} & -1 \\ 1 & -\frac{1}{2} & -\frac{1}{2} & -\frac{\sqrt{3}}{2} & \frac{\sqrt{3}}{2} & 0 \\ 0 & -\frac{\sqrt{3}}{2} & \frac{\sqrt{3}}{2} & \frac{1}{2} & \frac{1}{2} & -1 \\ 1 & 1 & 1 & 0 & 0 & 0 \\ 0 & 0 & 0 & 1 & 1 & 1\end{array}\right]$

By means of this transformation, the complex system of motor is decomposed into three decoupled communally orthogonal subspaces $(\alpha, \beta),(z 1, z 2)$ and $(01, o 2)$. The variables equations of the machine, under the assumptions [26] concerning sinusoidally distributed windings and the neglect of magnetic saturation and iron losses, can be represented in stationary frame by [11]:

$\left[V_{\alpha \beta}\right]=\left[R_{S}\right]\left[i_{\alpha \beta}\right]+\frac{\mathrm{d}}{\mathrm{dt}}\left[\Psi_{\alpha \beta}\right]$

$\left[V_{\alpha \beta}\right]=\left[R_{s}\right]\left[i_{\alpha \beta}\right]+\frac{\mathrm{d}}{\mathrm{dt}}\left[\left[L_{\alpha \beta}\right]\left[i_{\alpha \beta}\right]+\Psi_{\mathrm{PM}} \cdot\left[\begin{array}{l}\cos \theta \\ \sin \theta\end{array}\right]\right]$

$\left[V_{z_{1,2}}\right]=\left[R_{s}\right]\left[i_{z_{1,2}}\right]+\left[L_{z}\right] \frac{\mathrm{d}}{\mathrm{dt}}\left[i_{z_{1,2}}\right]$

$\left[V_{o_{1,2}}\right]=\left[R_{S}\right]\left[i_{o_{1,2}}\right]+\frac{\mathrm{d}}{\mathrm{dt}}\left[\Psi_{o_{1,2}}\right]$

$\left[V_{o_{1,2}}\right]=\left[R_{S}\right]\left[i_{o_{1,2}}\right]+\left[L_{o}\right] \frac{\mathrm{d}}{\mathrm{dt}}\left[i_{o_{1,2}}\right]$

Where:

$\mathrm{Ld}, \mathrm{Lq}$ are direct and quadrature-axis inductances.

$\mathrm{Lz}$ and Lo are the transformed inductance of stator selfleakage.

$\Psi_{\mathrm{PM}}$ is the flux linkage product by permanent magnet.

$\theta$ is the rotor position angle.

According to VSD approach [10], the fundamental component and harmonics with order $12 \mathrm{Kth} \pm 1(\mathrm{~K}=$ $1,2,3, \ldots)$ are located in the $(\alpha, \beta)$ subspace. The harmonics with order $6 K t h \pm 1(K=1,3,5, \ldots)$ are converted into the $(z 1, z 2)$ subspace. The harmonics with order $3 K t h(K=1,3,5, \ldots)$ are represented into the zero-sequence subspace $(01,02)$.
The $(\alpha, \beta)$ current components contribute to the electromechanical energy conversion; However, the currents in (z1, z2) and (o1, o2) are all harmonics, independent of the resultant torque and produce stator loss [27, 28].

In relation to change from stationary plane of $(\alpha, \beta)$ subspace to the rotating plane $(\mathrm{d}, \mathrm{q})$, the following transformation matrix is applied:

$T_{r}=\left[\begin{array}{cc}\cos \theta & \sin \theta \\ -\sin \theta & \cos \theta\end{array}\right]$

In the (d-q) subspace:

- the electric equation of the machine is shown as:

$$
\begin{aligned}
& {\left[\begin{array}{c}
\mathrm{V}_{\mathrm{d}} \\
\mathrm{V}_{\mathrm{q}}
\end{array}\right]=\left[\begin{array}{cc}
\mathrm{R}_{\mathrm{s}} & 0 \\
0 & \mathrm{R}_{\mathrm{s}}
\end{array}\right]\left[\begin{array}{c}
\mathrm{i}_{\mathrm{d}} \\
\mathrm{i}_{\mathrm{q}}
\end{array}\right]+\frac{\mathrm{d}}{\mathrm{dt}}\left[\begin{array}{c}
\Psi_{\mathrm{d}} \\
\Psi_{\mathrm{q}}
\end{array}\right]+\frac{d \theta}{d t}\left[\begin{array}{c}
-\Psi_{\mathrm{q}} \\
\Psi_{\mathrm{d}}
\end{array}\right]} \\
& {\left[\begin{array}{c}
\Psi_{\mathrm{d}} \\
\Psi_{\mathrm{q}}
\end{array}\right]=\left[\begin{array}{cc}
\mathrm{L}_{\mathrm{d}} & 0 \\
0 & \mathrm{~L}_{\mathrm{q}}
\end{array}\right]\left[\begin{array}{c}
\mathrm{i}_{\mathrm{d}} \\
\mathrm{i}_{\mathrm{q}}
\end{array}\right]+\sqrt{3}\left[\begin{array}{c}
\Psi_{\mathrm{PM}} \\
0
\end{array}\right]}
\end{aligned}
$$

- the mechanic equation of the machine is shown as:

$\Gamma_{e m}=p\left(i_{q} \Psi_{\mathrm{d}}-i_{d} \Psi_{\mathrm{q}}\right)$

( $p$ is the number of the pole pairs).

The Dual Three-Phase drive has 64 different voltage vectors. A decimal number, corresponding to binary numbers [Sa1 Sb1 Sc1 Sa2 Sb2 Sc2], is used to represent each vector. Where $(\mathrm{S}=\mathrm{Sa} 1, \mathrm{Sb} 1, \mathrm{Sc} 1, \mathrm{Sa} 2, \mathrm{Sb} 2, \mathrm{Sc} 2)$ are the device switch states. The phase voltages are expressed according to switch states by the following equation:

$\left[\begin{array}{l}V_{a 1} \\ V_{b 1} \\ V_{c 1} \\ V_{a 2} \\ V_{b 2} \\ V_{c 2}\end{array}\right]=\frac{\mathrm{E}}{3}\left[\begin{array}{cccccc}2 & -1 & -1 & 0 & 0 & 0 \\ -1 & 2 & -1 & 0 & 0 & 0 \\ -1 & -1 & 2 & 0 & 0 & 0 \\ 0 & 0 & 0 & 2 & -1 & -1 \\ 0 & 0 & 0 & -1 & 2 & -1 \\ 0 & 0 & 0 & -1 & -1 & 2\end{array}\right]\left[\begin{array}{l}S_{a 1} \\ S_{b 1} \\ S_{c 1} \\ S_{a 2} \\ S_{b 2} \\ S_{c 2}\end{array}\right]$

While:

- (S = Sa1, Sb1, Sc1, Sa2, Sb2, Sc2): switch's states;

- E: DC bus voltage.

By the matrix $\mathrm{T}$, the plane voltages function the device switch states can be expressed by:

$\left[\begin{array}{l}V_{\alpha} \\ V_{\beta} \\ V_{z 1} \\ V_{z 2} \\ V_{01} \\ V_{02}\end{array}\right]=T\left[\begin{array}{l}V_{a 1} \\ V_{b 1} \\ V_{c 1} \\ V_{a 2} \\ V_{b 2} \\ V_{c 2}\end{array}\right]$

Therefore, in two subspaces $(\alpha, \beta)$ and $(z 1, z 2)$, there are 60 non null voltage vectors and 4 zero ones $(0,7,56,63)$ which are shown in Figures 3 and 4 [29]. 


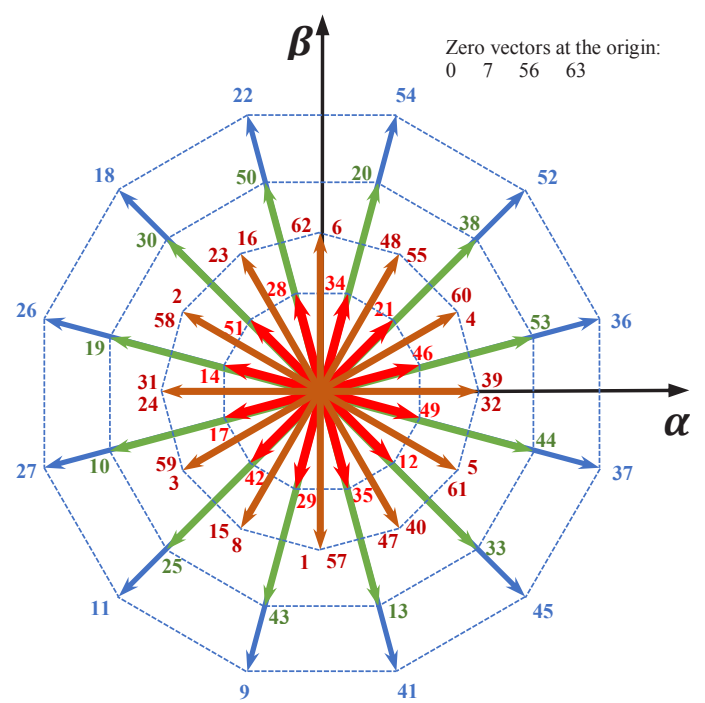

Fig3. Space vectors diagram in $(\alpha-\beta)$

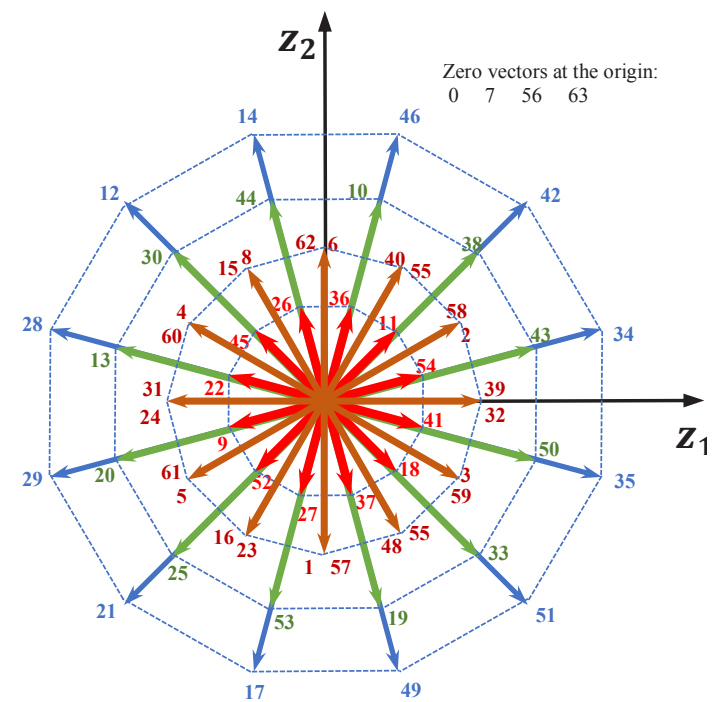

Fig. 4. Space vectors diagram in $\left(\mathrm{z}_{1}-\mathrm{z}_{2}\right)$

\section{DTC scheme}

In the basic DTC for DTP-PMSM, torque and flux are estimated. Torque and flux regulators are used to create the inverter vectors by using a switching table, (Fig. 5). In the $(\alpha, \beta)$ subspace, the 12 maximum magnitude vectors, which form 12 sectors, are chosen as depicted in Figure 6. The select of these vectors allows to have the smallest amplitude vectors in the $(z 1, z 2)$ subspace, and enables maximal exploitation of DC source.

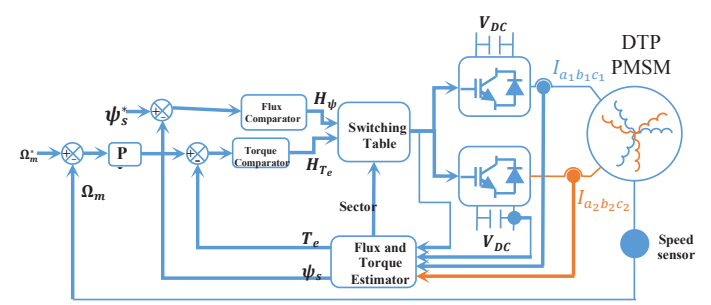

Fig. 5 DTC diagram of the machine.

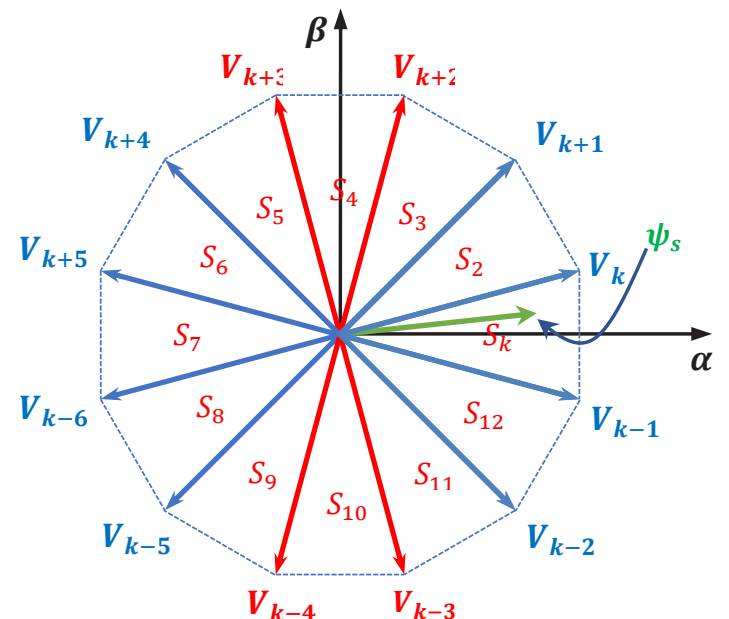

Fig. 6. Choice vectors once stator flux situated in sector k.

The $(\alpha, \beta)$ subspace is decomposed into 12 sectors; each sector is bordered using two maximum vectors, as shown in Figure 6. When the stator flux positioned in sector $\mathrm{k}$, vector viable for the rise of both flux and torque is $V_{k+2}$ where the one answerable for their reduction is $V_{k-4}$ and that responsible for the reduction of both flux and torque is $V_{k-4}$. Vector $V_{k+3}$ leads to the reduction of the flux and the increase of the torque whereas vector $\mathrm{V}_{\mathrm{k}-3}$ leads to the opposite process.

Torque and flux hysteresis regulators are employed to generate appropriate voltage vector according to table 1 .

Table 1. Switching table DTC of the machine

\begin{tabular}{|c|c|c|c|c|c|c|}
\hline & \multicolumn{6}{|c|}{ K Sector } \\
\hline $\mathrm{H}_{\Psi}$ & \multicolumn{3}{|c|}{1} & \multicolumn{3}{|c|}{-1} \\
\hline $\mathrm{H}_{\mathrm{T}_{\mathrm{e}}}$ & 1 & 0 & -1 & 1 & 0 & -1 \\
\hline $\begin{array}{l}\text { Applied } \\
\text { vector }\end{array}$ & $V_{k+2}$ & $V_{\text {zero }}$ & $V_{k-3}$ & $V_{k+3}$ & $V_{\text {zero }}$ & $V_{k-4}$ \\
\hline
\end{tabular}

The engendered torque and flux control signals $H_{\psi}$ and $H_{T_{e}}$ are defined by the following tables:

\begin{tabular}{|c|c|c|}
\hline Signal & Value & Condition \\
\hline \multirow{3}{*}{$\mathrm{H}_{\mathrm{T}}$} & 1 & $T_{e}^{*}-T_{e} \geq \varepsilon_{T}$ \\
\cline { 2 - 3 } & 0 & $T_{e}^{*}-T_{e}=0$ \\
\cline { 2 - 3 } & -1 & $T_{e}^{*}-T_{e} \leq \varepsilon_{T}$ \\
\hline
\end{tabular}

\begin{tabular}{|c|c|c|}
\hline Signal & Value & Condition \\
\hline \multirow{2}{*}{$\mathrm{H}_{\Psi}$} & 1 & $\psi_{S}^{*}-\psi_{s} \geq \varepsilon_{\psi}$ \\
\cline { 2 - 3 } & -1 & $\psi_{S}^{*}-\psi_{S} \leq \varepsilon_{\psi}$ \\
\hline
\end{tabular}




\section{Simulations Results}

The simulations with Matlab/Simulink environment, were accomplished by using a $240 \mathrm{~W}$ prototype DTPPMSM whose principal parameters are indicated in table 2 [25].

Table 2. The parameters of the machine

\begin{tabular}{|l|l|}
\hline \multicolumn{1}{|c|}{ Designation / symbol } & \multicolumn{1}{c|}{ Value/ unit } \\
\hline DC bus voltage / E & $400 \mathrm{~V}$ \\
\hline Statoric resistance / Rs & $1 \Omega$ \\
\hline Direct inductance / Ld & $8.5 \mathrm{mH}$ \\
\hline Quadrature inductance / Lq & $8.5 \mathrm{mH}$ \\
\hline Permanent magnet flux / $\Psi_{\mathrm{PM}}$ & $0.175 \mathrm{~Wb}$ \\
\hline Total inertia moment / J & $89.10-3 \mathrm{kgm} 2$ \\
\hline Total viscous friction coefficient / f & $0.01 \mathrm{Nms} / \mathrm{rad}$ \\
\hline Number of pole pairs / p & 4 \\
\hline
\end{tabular}

All together the simulations, the load torque is fixed at $8 \mathrm{~N} . \mathrm{m}$, the motor speed is constant at $300 \mathrm{rpm}$. The two studied strategy conventional DTC for DTP-PMSM drives, has been simulated and results are presented in figures 7 to 10 .

Figure 7 shows that the phase current using classical DTC strategy is not purely sinusoidal. Therefore the harmonic currents contain a big quantity of the 5 th and 7 th harmonics which are dominant $(\mathrm{THD}=42.6 \%)$ as shown in Figure 8. It is value mentioning that these stator current components do not contribute to the air gap flux and will only produce losses.

Figure 9 represents the currents in $(\alpha, \beta)$ subspace having a low ripple and a regular trajectory for the proposed method.

In figure 10 (a), the performance of the torque is not affected by the presence of these harmonics.

Figure 10 (b), shows the machine speed response; the velocity reaches its reference with good static and dynamic performance.

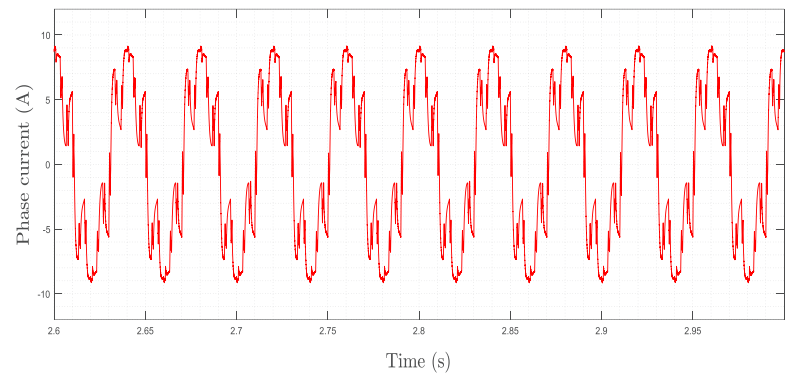

Figure 7. Current of stator phase

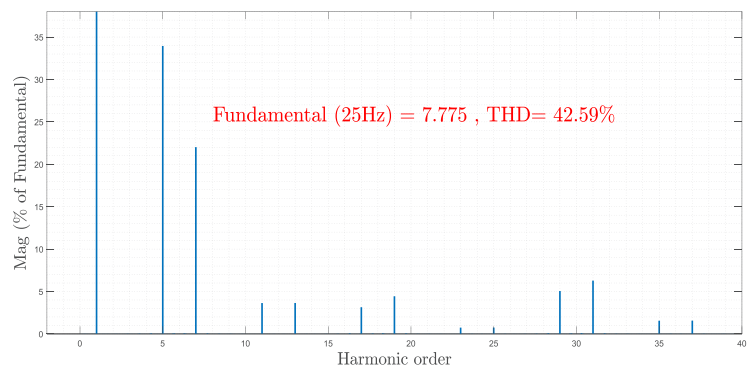

Figure 8. Spectrum of stator phase

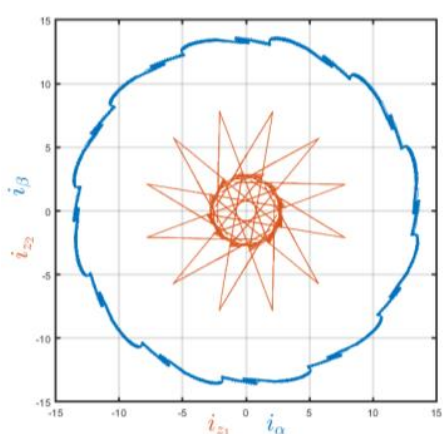

Figure 9. Stator current trajectory in $(\alpha, \beta)$ and $(\mathrm{z} 1, \mathrm{z} 2)$

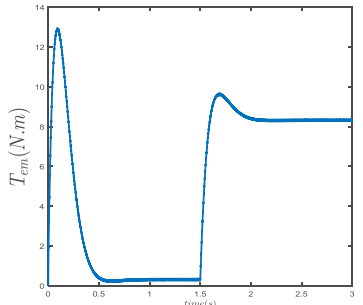

(a) Torque response

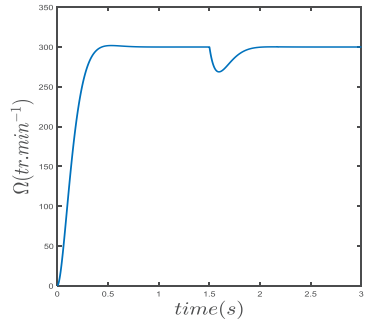

(b) speed response
Figure 10. Torque and speed response 


\section{Conclusion}

This paper presents a conventional Direct Torque Control (DTC) strategy to control the DTP-PMSM. When using its technique, only the variables in the subspace $(\alpha, \beta)$ are controlled but significant harmonic current will be produced. These harmonics do not contribute to the electromechanical energy conversion, however increase the stator loss. The conventional DTC based on regulators and Vector Space Decomposition (VSD) theory proposed in this paper can resolve the problematic effectively. This method permits the elaborating of the most appropriate inverter voltage vector which allows not only the control of variables in $(\alpha, \beta)$ subspace but also the diminution of currents in the $(\mathrm{z} 1, \mathrm{z} 2)$ subspace.The simulation results show that as well as the good dynamic response, this proposed technique can decrease the torque ripple and harmonic current and increase the system effectiveness.

\section{References}

1. M.Hasoun, A.El Afia, K.Chikh, M.Khafallah and K.Benkirane, "A PWM Strategy for Dual ThreePhase PMSM Using 12-Sector Vector Space Decomposition for Electric Ship Propulsion," 19th IEEE Mediterranean Electrotechnical Conference (MELECON), Mai 2-7, IEEE, 243248, (2018).

2. H. Echeikh, R. Trabelsi, H.Kesraoui, A.Iqbal and M.F.Mimouni, "Torque ripples improvement of direct torque controlled five-phase induction motor drive using backstepping control " International Journal of Power Electronics and Drive Systems, (IJPEDS), Vol. 11, No. 1, 64,74, March (2020).

3. A. Taibi, K. Hartani and A. Allali, "New DTC strategy of multi-machines single-inverter systems for electric vehicle traction applications," International Journal of Power Electronics and Drive Systems, (IJPEDS), Vol. 11, No. 2, 641,650, June (2020).

4. E.Levi, "Multiphase electric machines for variable-speed applications," IEEE Trans. Ind. Electron., Vol.55, 1893, 1909, (2008).

5. M. M. El Kholy and Z. M. S. El Barbary, "Performance Analysis of indirect rotor field orientation five phase induction motor using eight switch inverter," International Journal of Power Electronics and Drive Systems, (IJPEDS), Vol. 8, No. 3, 1128,1138, September (2017).

6. M.B.R. Corra, C. B. Jacobina, C.R. da Silva, A.N. Lima and E.R.C. da Silva, "Six-phase AC drive system with reduced common-mode voltage", IEEE International Electric Machines and Drives Conference, 1852, 1858, (2003).

7. A. K. Mohanty and K. B. Yadav, "Estimation of excitation capacitance requirement of an isolated multi-phase induction generator for power generation," International Journal of Power
Electronics and Drive Systems, (IJPEDS), Vol. 7, No. 2, 561,567, June (2016).

8. Drazen Dujic, Atif Iqbal and Emil Levi, “A Space Vector PWM Technique for Symetrical Six-Phase Voltage Source Inverters", EPE Journal, Vol.17, No.1, 24, 32, (2007).

9. Yanjun Yu, Lixiao Gao, Yang Liu and Feng Chai, "24-Sector space vector decomposition for a dual three-phase PMSM," 2014 17th International Conference on Electrical Machines and Systems (ICEMS), oct 22-25, Hangshou, China, 1601,1606, (2014).

10. Y. Zhao and T. A. Lipo, "Space vector PWM control of dual three-phase induction machine using vector space decomposition", IEEE Trans. Ind. Applicat., Vol.31, No.5, 1100,1109, (1995).

11. M. Hasoun, A.El Afia, M.Khafallah and K. Benkirane, "Experimental implementation a PWM strategy for dual three-phase PMSM Using 12sector vector space decomposition applied on electric ship propulsion", International Journal of Power Electronics and Drive System (IJPEDS), Vol. 11, No. 4, 1701, 1710, December (2020).

12. L Wang, D Zhang, Z. Wang, J.Chen, M.Cheng and N.Ren "Vector space decomposition based control of neutral-point-clamping (NPC) three-level inverters fed dual three-phase PMSM Drives," IECON 2016- 42nd Annual Conference of the IEEE Industrial Electronics Society, Oct 16, IEEE, 2988,2993, (2016).

13. Z. Wang, Y. Wang, J. Chen and Y. Hu, "Decoupled Vector Space Decomposition Vector Based Space Vector Modulation for Dual Threephase Three-level Motor Drives," IEEE Trans. Ind. Applicat., Vol.33, No.12, 10683,10697, (2018).

14. L. Yuan, M.-L. Chen, J.-Q. Shen, and F. Xiao, "Current harmonics elimination control method for six-phase PM synchronous motor drives," ISA Transactions, Vol. 59, 443 , 449, (2015).

15. Valentin Oleschuk et al "Combined PWM control of multi-inverter installation with two DC-links", 2015 International Conference of Electrical Drives and Power Electronics (EDPE), 94, 98, (2015).

16. H. Zhang et al, "Study on series control method for dual three-phase PMSM based on space vector pulse width modulation", International Journal of Control and Automation, Vol. 8, No. 1, 197, 210 , (2015).

17. Khoudir Marouani, Lotfi Baghli, Djafar Hadiouche, Abdelaziz Kheloui, and Abderrezak Rezzoug, "A New PWM strategy based on a 24sector vector space decomposition for a six-phase VSI-fed dual stator induction motor", IEEE Trans. Ind. Applicat., Vol. 55, No. 5, 1910,1920, (2008).

18. R.Kianinezhad, B. Nahid, F. Betin, G.A. Capolino, "A novel Direct Torque Control (DTC) method for dual three phase induction motors," IEEE International Conference on Industry Technology, Mumbai, India, 939-934, (2006). 
19. A. Khajeh, J.S. Moghani and M. Shahbazi, "An efficient direct torque control scheme for split phase induction motor," $7^{\text {th }}$ International Conference on power Electronics and Drive System, Bangkok, Thailand, 1285, 1289, (2007).

20. R. Bojoi, F. Farina, G. Griva, et al, "Direct torque control for dual three phase induction motor drives," IEEE Transactions on Industry Applications, vol. 41, No. 6, 1627,1636, (2005).

21. D. Yazdani, S. A. Khajehoddin, A. Bakhshai, et al, "Full utilization of the inverter in split-phase drives by means of a dual three-phase space vector classification algorithm," IEEE Transactions on Industry Electronics, vol. 56, No. 1, 120,129, (2009).

22. G. Grandi, G. Serra, A. Tani, "Space vector modulation of a six-phase VSI based on threephase decomposition," International Symposium on Power Electronics, Electrical Drives, Automation and Motion, Ischia, Italy, 674,679, (2008).

23. C. Lascu, I. Boldea and F. Blaabjerg, "A modified direct torque control for induction motor sensorless drive," IEEE Transactions on Industry Applications, vol. 36, No. 1, 122,130, (2000).

24. Yen-Shin Lai, Jian-Ho Chen, "A new approach to direct torque control of induction motor drives for constant inverter switching frequency and torque ripple reduction," IEEE Transactions on Energy Conversion, vol. 16, No. 3, 220-227, (2001).

25. K.Dang Hoang, Yuan Ren, Z.Q.Zhu and Martin Foster,"Modified switching-table strategy for reduction of current harmonics in direct torque controlled for dual three-phase permanent magnet sychronous machine drives,' IET Electr. Power Appl., 2015, Vol.9, Iss.1, 10, 19, (2015).

26. Ping Zhang, Wei Zhang and Xiaofeng Shen, and O. Pyrhonen, "Comparative study of field-oriented control in different coordinate systems for DTPPMSM", International Conference on Electrical Machines and Systems (ICEMS), Oct.26-29, 1015,1019, (2013).

27. M. Hasoun, A.El Afia, M.Khafallah and K. Benkirane, "Performance comparison of twoSVPWM-strategies based vector space decomposition controlled dual three-phase PMSM for electric ship propulsion", 7th International Renewable and Sustainable Energy Conference, (IRSEC), 27, 30 November (2019).

28. M. Hasoun, A.El Afia, M.Khafallah and K. Benkirane, "Field oriented control of dual threephase PMSM based space vector decomposition for electric ship propulsion", International Conference of Computer Science and Renewable Energies, (ICCSRE), 1,6, 22 August (2019), IEEE/ICCSRE 2019, 22-24 July, Agadir, Morocco, (2019).

29. M. Hasoun, A.El Afia, M.Khafallah and K. Benkirane, "Field oriented control based on a 24sector vector space decomposition for dual three- phase PMSM applied on electric ship propulsion", International Journal of Power Electronics and Drive System (IJPEDS), Vol. 11, No. 3, pp. 1175 , 1187, September (2020). 